\title{
Buyers' trust and mistrust in e-commerce platforms: a synthesizing literature review
}

\author{
Marzieh Soleimani $^{1}$ D
}

Received: 19 January 2021 / Revised: 1 October 2021 / Accepted: 21 October 2021 /

Published online: 11 November 2021

(c) The Author(s), under exclusive licence to Springer-Verlag GmbH Germany, part of Springer Nature 2021, corrected publication 2022

\begin{abstract}
Electronic markets have grown substantially, and they are considered an effective form of retail in recent years. Despite such growth, lack of physical transactions between different parties, as well as users' concerns about their privacy and security of transactions in electronic commerce (e-commerce) platforms have jeopardized users' trust. Thus, trust as a key issue for reducing consumers' perceived risk and the successful promotion of e-commerce has motivated many researchers to study it. This paper created a comprehensive and up-to-date framework that synthesized the previous studies in the literature conducted on trust in e-commerce environments. A systematic literature review method was selected to achieve this aim. The initial search in 17 top-ranked information systems journals and conferences resulted in 129 papers that met the inclusion criteria. Then these studies underwent an in-depth examination to determine how trust had been conceptualized in e-commerce environments. Further, the theoretical bases in relation to trust in e-commerce contexts used in the literature were investigated. The study concludes with implications for practice and a critical agenda for future research.
\end{abstract}

Keywords Trust · Electronic commerce platforms · Online shopping $\cdot$ Systematic literature review

\section{Introduction}

Trust is of high significance that has been argued "a complete lack of trust would prevent [us] from getting up in the morning" (Luhmann 2018, p. 4). Moreover, this concept has an ever-evolving history, going from restricted trust to family and friends to strangers in peer-to-peer platforms (Mazzella et al. 2016). Specifically,

Marzieh Soleimani

m.solaymani@alumni.ut.ac.ir

1 Faculty of Management, University of Tehran, Tehran, Iran 
this concept has found its way into electronic commerce (e-commerce), which is perceived as a critical factor for success in online commerce (Chang et al. 2013) because it is considered as an essential factor separating buyers from non-buyers (Kim and Park 2013).

In a survey examining 6000 customers' data, trust in e-commerce platforms was given more importance, even, than price (Ernst and Young 2000). However, similar surveys showed that a small number of users could trust these platforms, especially when their privacy and security came into conflict (Connolly and Bannister 2007). With the growth of e-commerce as a market and economic force over the past two decades (Lim et al. 2006), the concept of trust has inevitably attracted many researchers' attention, causing to have been studying it using some models from various disciplines.

While several reviews have examined antecedents and consequences of online trust (e-trust), there appears to be confusion regarding the attribute in which e-trust is developed (Kim et al. 2006). According to Forbes, global e-commerce sales surged rapidly, from 2.9 trillion U.S. dollars in 2020 to 4.2 trillion U.S. dollars in 2021 (Verdon 2021). In addition, the COVID-19 pandemic has created an increasing desire to switch to online modes of shopping (Barnes 2020). Therefore, the growing number of studies and changes in online marketing necessitates an updated and comprehensive literature review taking various dimensions of trust, including the studies' theoretical bases into account.

Few, if any, systematic literature review has yet been done on the role of trust in e-commerce platforms, investigating the antecedents leading to improving trust in e-commerce platforms; and thus to help practitioners develop a framework for improving their platforms. Accordingly, the following research questions were sought:

RQ1. What factors are mentioned in the literature do affect trust in e-commerce platforms?

Furthermore, this study investigates the impact of trust on both other tangible and intangible features of e-commerce websites. Therefore, answering this second research question can help the investigation to illustrate the effects and benefits of e-trust better:

RQ2. What are the consequences of trust in e-commerce put forth in the literature?

Finally, the study looks at the theoretical concepts and areas used in the literature and synthesizes them in a single framework that can inform future studies. A third research question is proposed to cover this aspect of the research:

RQ3. What are the possible implications of the present study for future research?

The rest of the paper is structured as follows: an overview of the theme of trust in electronic commerce research is presented in Sect. 2. Section 3 outlines the steps of this literature review and the criteria for including and excluding research papers in 
the final analysis. In Sect. 4, the literature review results are presented and explained. These results are further discussed in Sect. 5 by outlining the contributions to theory and practice with an agenda for future research, and the study concludes in Sect. 6.

\section{Background}

Various scholars have provided different definitions for trust based on their outlook. McKnight et al. (2002) categorized these definitions into two groups: conceptual types and referents types. Conceptual types include attitudes, beliefs, behaviors, and dispositions, whereas referent types include trust in something, trust in someone, or trust in a specific characteristic of someone (e.g., honesty). Later, drawing on this categorization, McKnight furthered different types of trust, including disposition to trust, which means one's general disposition to trust others; institutional trust, which means one's trust in situations or structures; and interpersonal trust, such as trust in e-vendor. These led to the multidimensional definitions of trust: "to willingly become vulnerable to the trustee, whether another person, an institution or people generally having taken into consideration the characteristics of the trustee."

Mayor, on the other hand, listed three varying perspectives for trust, including psychology (a tendency to trust others), social psychology (cognition considerations of a trustee), and sociology (characteristics of the institutional environment). With this respect, Mayor defined trust as "the willingness of a party to be vulnerable to the actions of another party based on the expectation that the other will perform a particular action important to the trustor, irrespective of the ability to monitor or control that other party" (Mayer et al. 1995, p. 712, Chiu et al. 2019; Tomlinson et al. 2020). Although this definition seems outdated, it has been used in recent publications and is considered the primary source of trust definition in e-commerce literature. The article in which this definition was published has been getting thousands of citations every year, and in total, it has been cited over 25,000 times.

The notion of trust has been an area of interest in organization studies and information systems for decades (Mayer et al. 1995; Li et al. 2008). In particular, the concept of electronic commerce trust was initiated in the late 1990s, with studies focusing on trust antecedents (Fung and Lee 1999). Earlier reviews have studied some limited aspects of trust, including the impact of uncertainty, the (new) meaning and typology of trust (Grabner-Kräuter and Kaluscha 2003; McKnight and Chervany 2001), the use of existing theories regarding trust (Huang et al. 2007), and the early models of trust (Papadopouou et al. 2001). However, the recent advancements and changes in electronic markets and the massive amount of work published in the past years are not assumed mainly beneficial for providing insight into state-of-the-art research.

Previous studies have also reviewed the impact of trust on disruptive models and platforms used in electronic markets. As an illustration, in a study conducted by Hawlitschek et al. (2018) in the context of sharing economy, trust was categorized into "trust in peers" and "trust in the platform". In the end, they suggested blockchain as a technological solution to improving trust. In the realm of e-commerce, several systematic literature reviews were sought to understand the importance and 
the evolving nature of trust. Beldad et al. (2010), for instance, examined antecedents of trust for commercial and non-commercial online firms, realizing that there were a host of antecedents for which they designed a framework, including three clusters: customer/client-based, website-based, and company/organization-based. A meta-analysis on this topic was carried out by Kim and Peterson (2017), surveying 150 empirical studies revealed that antecedents such as perceived service quality, perceived privacy, and perceived reputation were inherently associated with the antecedents of online trust. The study also listed the consequences, often dealt with mentioned in previous empirical studies, including satisfaction, attitude, loyalty, repeating purchase intention, and intention to use the website. While, so far, the systematic literature reviews have mainly focused on the antecedents and consequences of trust, factors such as disposition to trust, security, familiarity, and risk perception received less attention.

Although extensive research has been carried out on trust in e-commerce, few writers have thus far striven to draw on a systematic literature review, focusing on the characteristics of the antecedents and consequences of trust in the context of electronic commerce. Therefore, the current study was motivated to shed light on this area by focusing not only on the components of research models but also on the theoretical concepts deeply.

\section{Methodology}

To investigate the factors leading to and impacted by trust in the electronic commerce environment, the Systematic Literature Review (SLR) approach was adopted, being a methodical way to identify, evaluate, and interpret the available empirical studies conducted on a particular topic, research question, or phenomenon of interest (Kitchenham 2004). Considering the research aims in this study, the SLR approach was built on synthesizing the available literature by summarizing and organizing published articles, as well as clarifying how prior literature has contributed to knowledge development in this area (Schryen et al. 2020). To do so, First, 17 highranked IS journals and conferences, among the considerable number of research conducted on trust in e-commerce, were selected as a representative of the whole body of knowledge and searched with a predefined set of keywords. It is important to add that the reasons behind selecting those top journals and conferences were IS journals' available rankings (Fisher et al. 2007), previous SLR work (Tallon et al. 2019; Amrollahi et al. 2013), and their tendency for emphasis on e-commerce and related areas. Also, it should be noted that the focus of selected conferences was AIS sponsored conferences, including ICIS, PACIS, ECIS, and AMCIS. Then, through the initial search, 601 papers were found. Then, irrelevant articles were excluded after reviewing papers' titles, abstracts, and full texts. The final set of papers were investigated against the research questions in this study. 


\subsection{Keywords}

To select the keywords with the best results, Scopus was first searched using broad keywords "trust in electronic commerce" and "online shopping trust." After reviewing the first ten pages of the search results, the keywords were refined. Finally, the following terms were applied to limit the search in titles, keywords, and abstracts in the search engine: Trust AND ("retail" OR e-commerce" OR "electronic commerce" OR "electronic business" OR "e-business" OR "shop" OR "sale" OR "buy" OR “purchase" OR “e-Trust” OR “market”).

Table 1 An overview of selected outlets shows the outlets used as the sources for this study, the rationale for selecting the outlet, and the number of papers found in each outlet.

\subsection{Data extraction and analysis}

The initial search ran based on the above keywords in October 2019. To build a meticulous review of the recent literature, with the articles published in the past twenty years, a time span from 2000 was defined. The first stage search reached 601 studies. After limiting the document types to only articles and conference papers by excluding book chapters, books, reviews, conference reviews, and short surveys, as well as filtering the subject areas to business, management, and accounting, social science, economics and finance, decision sciences, arts and humanities, and psychology, I ended up with 482 studies. In the next step, to choose the relevant studies, among which their titles and abstracts were screened while putting emphasis on the role of trust, the way of its development, and its consequences in exclusively e-commerce environments, which led to obtaining a total of 129 studies for main and in-depth investigation. For this reason, technical articles excluded those investigating trust in contexts other than electronic commerce such as tourism, sharing economy, Internet of things, and those that focused on different aspects, including supply chain.

\subsection{Data analysis}

To analyse the final list of articles, first, they were differentiated based on their perceptions of trust and the different theories they used. Then, content analysis was performed to extract the factors that were believed to impact various forms of trust, along with its potential consequences in electronic markets. Afterward, these factors were categorized into multiple groups. To triangulate the data, the whole set of papers and the finalized categories of factors impacting trust and its consequences were presented to two colleagues with expertise in e-commerce to check them and create their own categories. The results of the data analysis are explained in the following section (Fig. 1). 


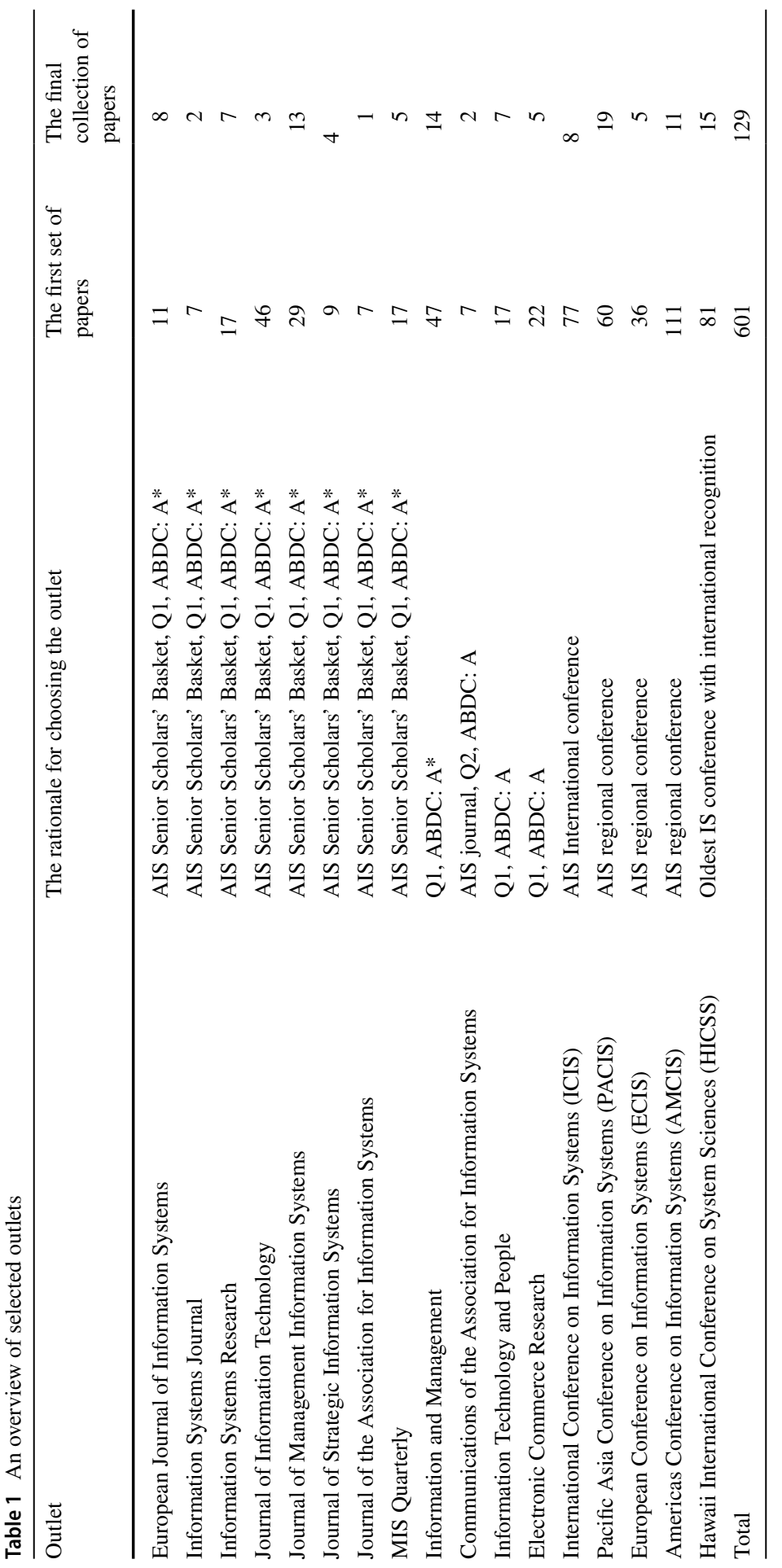




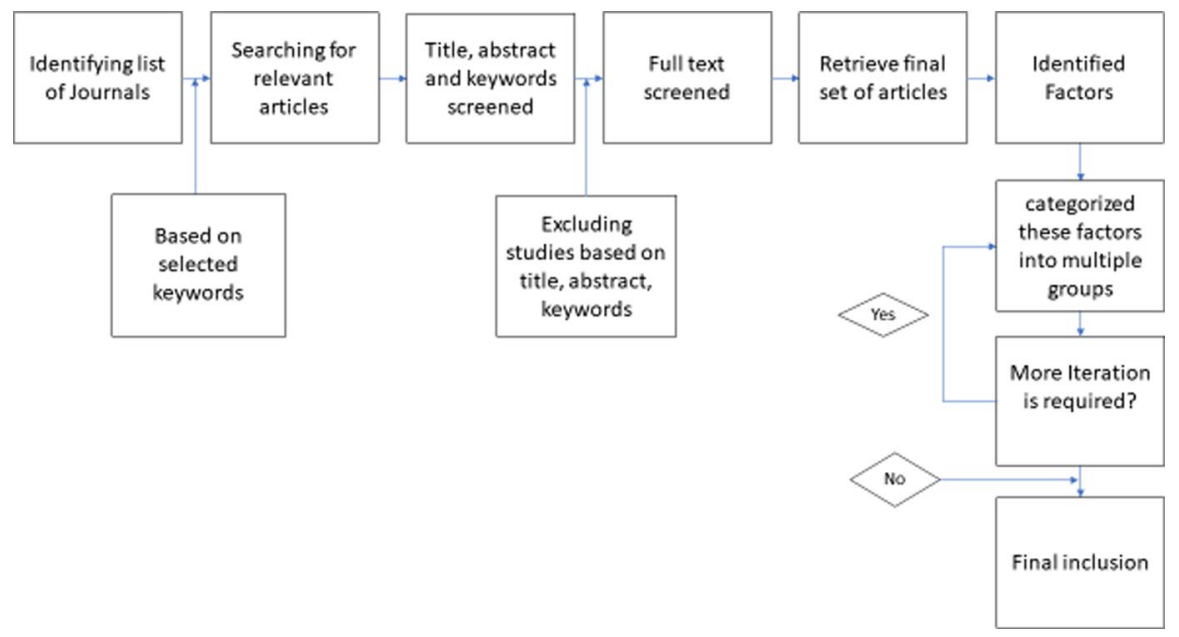

Fig. 1 Stages of research methodology

\section{Results}

\subsection{Theories}

By meticulously examining the literature review, 29 theories from various disciplines were found, including Marketing, Psychology, Economy, Sociology, Management and Organization Science, Computing, Information Systems, and Philosophy. It should be noted that due to the interdisciplinary characteristics of many of these theories in most cases, the origin of the discipline, where it had been published, was checked. Then, I probed into each theory to see if and how the constructs might fit into the notion of trust in e-commerce. Among these, Technology Acceptance Model (Davis et al. 1989; Venkatesh and Davis 2000) and Theory of Planned Behavior (Ajzen 1991) had been cited most as explained the processes leading to trust-related behavior and how technological components can be trusted in an e-commerce environment.

Concerning trust theories within the discipline of marketing, Signalling Theory (Spence 1974) and Expectation Confirmation Theory (Li et al. 2015), had been cited in the literature to explain customers' behavior in seeking relevant information and modeling factors, leading to their satisfaction. Typically, marketing theories look at social factors that influence trust; on the other hand, psychological theories mainly focus on customers' individually trusting behavior. Finally, sociological and organizational theories, such as Social Exchange Theory (Woisetschläger et al. 2011) and Social Capital Theory (Coleman 1988), are used to model social relationships between human actors and how trust can be developed as a result of these interactions.

As illustrated in Fig. 2, four elements were identified to be considered as the antecedents in these theories, including intention, behavior, consequence, and environmental factors. Such antecedent factors can result in a specific behavior. 


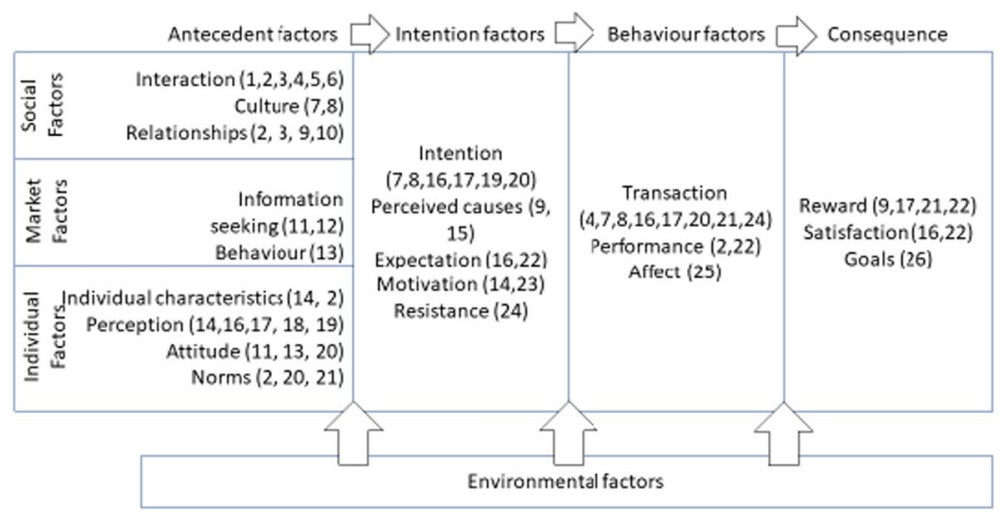

1. Stakeholder Theory, 2.Social Capital Theory, 3.Soxid Network Theory, 4.Social Presence Theory (SPT), 5. Theory of Social Responses to Computers, 6. Toulmin's Model of Argumentation, 7. Hofstede Cultural Theory, 8. Fukuyama Theory of Trust, 9. Soxial Exchange Theory, 10. Trust Transfer Theory, 11. Attribution Theory, 12. Economics Of Information Theory, 13. Elaboration Likelihood Model, 14. Theory of Impression Management, 15. Attribution Theory, 16. Associat ve Network Model of Memory 16. Cognitive Dissonance Theory, 17. Tam, 18.Attraction Theory, 19. Social Presence Theory (SPT), 20. Theory of Planned Behavior, 21. Tieory of Reasoned Action, i2. Expectation Confirmation Theory, 23. Commitment Theory of Relationship Marketing, 29. Status-quo Blas Theory, 25. Social Cognitive Theory, 26. Cognitive-affective Mediating Process

Fig. 2 Synthetization of theories in the final set of research studies

More specifically, such antecedents usually lead to a set of factors, broadly named intention factors by which any intrinsic motivation or resistance to perform a behavior can be triggered and resulting in some consequences, such as reward or satisfaction. Furthermore, in e-commerce trust literature, we also found three other different antecedent factors based on the theory's level and origin (individual, market-related, and social factors).

In Fig. 2, the numbers in front of each item shows the theories used in the particular component. For example, TAM depicted with number 17, posits perceived usefulness and perceived ease of use (being a part of perception in antecedent factors) as an individual's intention to use a system (being a part of intention in intention factors); also, intention of an individual as a mediator of actual system use (being a part of transaction in behavior factors and reward in consequences).

\subsection{Types of trust}

As a part of the systematic literature review, I tried to carefully examine and differentiate various types of trust in the e-commerce context. To differentiate these types of trust, I found multiple stakeholders in a trusted transaction and the mechanism that they trust each other. Under such scrutiny, I recognized four types of trust and demonstrated them in Table 2. 


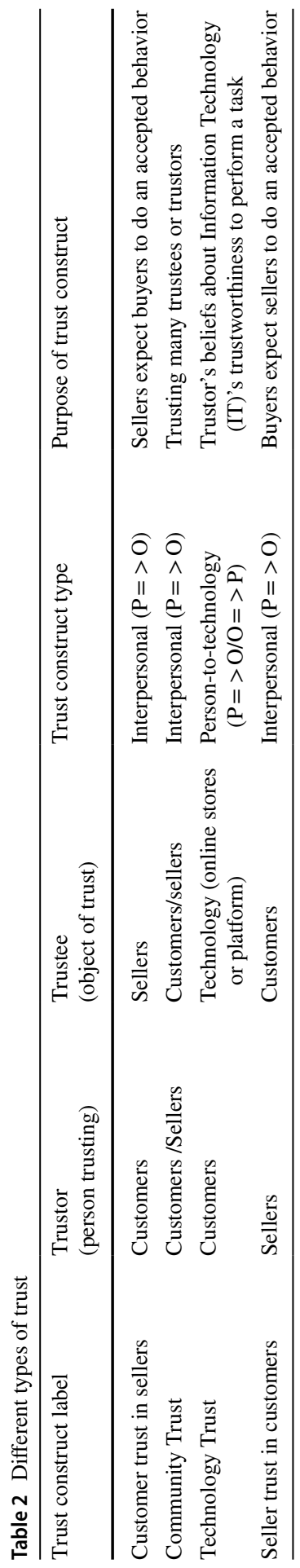




\subsubsection{Customers' trust in sellers}

The most common type of trust we found in this study is when customers as trustors expect another party (usually sellers) to do an accepted behavior. For example, Carter et al. (2014) studied the impact of trust on travelers' loyalty to online service providers. While many studies have focused on the effect of trust on behaviors, like performing a transaction (McKnight et al. 2002; Pennington et al. 2003; Kim et al. 2009), other studies have looked at long-term factors like loyalty (Li et al. 2015) and adoption of e-commerce (Pavlou and Fygenson 2006).

\subsubsection{Community trust}

Community trust serves as a generalized trust (one-to-many). It refers to trusting many trustees or trustors, especially those considered an unknown group of sellers or buyers, with the help and support of a specific online marketplace (Pavlou and Gefen 2004). It suggests that there would be a slight possibility for online buyers encountering the same seller twice in this research category (Pavlou and Gefen 2004). Sun (2010, p. 6) defined trust in the community of buyers as a "seller's subjective beliefs that buyers will behave in accordance with the seller's confident expectations by showing ability, integrity, and benevolence."

\subsubsection{Technology trust}

In this study, we considered trust in online shopping as a shopping mode, the Internet as an online store or platform, and social commerce websites as elements of technology trust. McKnight (2005) defined technology trust as the trustor's beliefs in Information Technology (IT)'s trustworthiness to perform a task. With higher reliance on technology in recent years, trust in technology has gained more attention, too. For instance, upon conducting an online purchase, customers expect the technological infrastructures to provide appropriate conditions to help with online tracking, online supports, pictures, quality, and information specificity. However, technology trust is considered beyond transaction fulfillment as many websites offer such features, including product recommendations, product comparisons, and customer reviews ( $\mathrm{Li}$ et al. 2009).

\subsubsection{Sellers' trust in customers}

Although there are many studies conducted on the role of trust in sellers, far too little attention has been paid to sellers' trust in other stakeholders, especially buyers. In this line, Sun (2010), in his study, mentioned that there is a substantial difference in trust behavior between sellers and buyers, stemming from various technical, political, and institutional dimensions. Therefore, sellers' trust is defined as the willingness of sellers to risk participating in a transaction, even when uncertainties occur. Sellers need to trust that buyers can make transactions with competence, benevolence, and integrity (Chong et al. 2003; Resnick and Zeckhauser 2002). For instance, Guo et al. (2018) surveyed Chinese sellers in a Business-to-Business (B2B) platform 
to understand the mechanism under which they could trust an online trading transaction. Similarly, in other studies, the possibility of a transaction as the outcome of B2B model was considered (Sun and Zhang 2008).

\subsection{Antecedents to trust}

As explained in the methodology part, after analyzing the final set of papers, the factors that impact trust, along with outcomes for online trust were extracted and categorized into different groups. In this section, you can see these categorized factors in detail as antecedents and consequences of trust.

Antecedents to trust are categorized based on various actors in an online transaction. Figure 3 illustrates these identified categories, which are customer-related antecedents, seller-related antecedents, technology and third-party antecedents, and environment-related antecedents. The findings of this section allow us to begin answering RQ1: What factors are mentioned in the literature do affect trust in e-commerce platforms. The remainder of this section explains each category in more detail.

\subsubsection{Customer-related antecedents}

Understanding the antecedent of customers' trust can provide invaluable insights into the factors that can possibly urge them to create trust and improve their intentions to make an online transaction. Based on the literature, customer concerns, disposition to trust, trusting beliefs, familiarity, calculative-based trust, accessibility of information, and other similar terms were considered as the main antecedents for this category.

In e-commerce, the process of building trust for customers is affected by customers' concerns, which are considered severe obstacles in electronic transactions (Agag et al. 2020; Kim 2008). According to the literature, four primary concerns for online customers are privacy, security, perceived technology risk, and integrity concerns (Connolly and Bannister 2007; Shukla 2014).

Disposition to trust, also known as propensity to trust, is "the extent to which a person displays a tendency to be willing to depend on others across a broad spectrum of situations and people" (McKnight et al. 2002, p. 339). McKnight and Chervany (2002) suggested that the effects of dispositional factors on trust are more than other

Fig. 3 The relationship among identified antecedents of trust

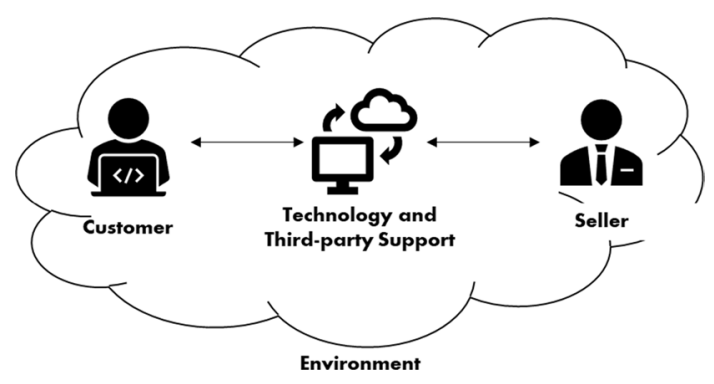


factors such as institution-based trust. Such a general propensity to trust in others can influence the intentions and beliefs of trustors about e-vendors.

Another type of customer-related antecedent is familiarity, which relates to a customer's prior behavior. Bhattacherjee (2002, p. 220) noted that "familiarity refers to one's understanding of another's behavior based on prior interactions or experiences." He also mentioned that familiarity gradually develops over time as trustees become accustomed to trustors' behavior and, in turn, improve trust in online buyers.

Based on calculative-based trust, an online customer can build trust through cost-benefit analysis of trustees whose behavior shows whether they are cheating or cooperating. Since calculative-based trust is deterrence-based, customers will not engage in opportunist behavior when they feel that the e-vendor is untrustworthy. Customers will trust e-vendors when they believe that the e-vendor either has more to lose by cheating or has nothing to gain by breaking the consumer's trust (Gefen et al. 2003a).

\subsubsection{Seller related antecedents}

The second category of factors that has an impact on trust is those related to sellers. Elements such as institution-based trust, reputation, communication, and interaction are considered sellers' characteristics in the literature.

As the first characteristic of sellers studied in the literature, reputation refers to the extent to which a trustee believes that a trustor has integrity and is concerned about its consumers (Kit et al. 2013). Researchers seem to have adopted different terms, referring to reputation, such as perceived effectiveness of feedback mechanism, brand awareness, brand image, perceived accreditation, portal affiliation, and online aesthetic appeal. In fact, these researchers in their studies indicated that reputation leads to trust in the e-commerce context. Therefore, there is a positive relationship between reputation and online trust (Hoffmann et al. 2014; Kit et al. 2013; Shiau and Chau 2015). In a similar vein, other researchers suggest that reputation has a vital role in engendering trust and in repurchase intention (Qureshi et al. 2009).

Effective communication is also another element regarded as crucial for trust in e-commerce. Moreover, interpersonal relationships or the ability to interact intimately in social networks are considered examples of trust antecedents in this category. And finally, institution-based mechanisms such as warranty and structural assurance are significant factors leading to trust in e-commence (Huang et al. 2005; Wang and Benbasat 2008).

\subsubsection{Technology and third-party related antecedents}

The positive impact of website quality and third-party institutions on trust has been supported in many studies. For instance, Jones and Leonard (2008) examined trust in customer-to-customer (C2C) environments. They confirmed that when customers do not know each other in online environment, they take cues from social signals, including website quality and third-party institutions. Perceived website quality 
demonstrates user's perceptions of some features such as the ease of use and usefulness of information (Awad adn Ragowsky 2008). Web users need to feel the website is well designed, organized, timely, and accurate to believe web vendors' trustworthiness (Flavin et al. 2006; Qureshi et al. 2009).

The role of intermediaries in developing consumers' trust in e-commerce markets is remarkably important, especially for small e-vendors (Datta abd Chatterjee 2008). McKnight and Chervany (2002) believe that since trust is transferable, an intermediary can have such responsibility for transferring consumers' trust in a brand to e-vendors. With this regard, Pavlou and Gefen (2004, p. 44) defined an online intermediary as a "third-party institution that uses internet infrastructure to facilitate transactions among buyers and sellers in its online marketplace by collecting, processing, and disseminating information." Consumers need to receive strong signals to trust other parties. A trusted third party, thus, can play this role to facilitate transactions (Clemons et al. 2016). Intermediaries can reduce the risk of making transactions in an e-commerce environment by producing a reliable and secure environment, instantiating fair and open rules and procedures, presenting accredit and evaluation, getting rid of problematic sellers, and encouraging benevolent transaction norms. In this way, for instance, some intermediaries such as eBay and Amazon try to reduce transactions risk by providing coverage up to a limit of $\$ 250$ to guarantee their auction transactions so that buyers could reduce their actual risk in transactions (Pavlou and Gefen 2004).

For sellers, online intermediaries can help them obtain market signals, reduce search costs, discover better prices, deliver products at a lower price, facilitate transaction settlements, and monitor buyers (Giaglis et al. 2002). Sellers need to trust that the intermediary performs these functions honestly, competently while having the interests of sellers in mind.

\subsubsection{Environment-related antecedents}

According to the literature, environment antecedents consist of word of mouth (WOM), culture, trusting beliefs, and perceived size. E-WOM is at the center of consumer behavior and is defined as any positive, negative, or neutral comments, recommendations or statements about a product, service, brand, or company based on prior experiences and knowledge created by former, potential, or actual web users. E-WOM will usually spread via the Internet and social networks (Hennig-Thurau et al. 2004). An influential study with respect to the investigation of e-WOM and its effect on trust by Awad and Ragowsky (2008) approved that e-WOM quality can positively impact online trust. Kim (2008) also supported the idea that positive referrals and posts can directly affect customer's trust in an e-vendor.

Regarding investigating the impact of culture on trust and consumer behavior, previous studies have mainly employed Hofstede's cultural dimensions. He defined culture as "the collective programming of the mind that distinguishes the members or category of people from another" (Hofstede et al. 2010, p. 6). Hofstede's original four dimensions of culture, including uncertainty avoidance, power distance, collectivism, and masculinity, have been frequently studied in the e-trust literature. Some studies focused on examining the effect of uncertainty avoidance on trust and online 
consumer behavior (Bui et al. 2013; Hwang 2005), while other studies have cited individualism/collectivism as a primary antecedent of trust in Internet shopping (Sia et al. 2009).

\subsection{Consequences of trust}

Different studies demonstrate various outcomes for online trust. For instance, McKnight et al. (2002) stated that online trust significantly affects online consumers' purchase intention; similarly, Sun (2010) referred to the positive impact of trust on repurchase intention. Trust can change risk perception, consumer attitude, and consumer's perception regarding website and seller (Jarvenpaa et al. 2000). Trust can also result in e-loyalty and satisfaction in online shopping procedures (Honglei Li et al. 2015; Shankar et al. 2002). The results of this section provides an answer to RQ2: What are the consequences of trust in e-commerce put forth in the literature? Each category related to the consequences of trust is discussed below in more detail.

\subsubsection{Transaction intention}

Transaction intention is the trustor's willingness to participate in an online transaction with a trustee (McKnight et al. 2002; Pavlou and Gefen 2004). According to the theory of reasoned action (TRA), trust can be regarded as a behavioral belief that makes a positive attitude toward purchase intention (Jarvenpaa et al. 2000; Pavlou and Gefen 2004). As discussed earlier, this behavioral intention is a common component in many other theories used in online trust literature. Consistent with previous studies in the literature, online consumer trust demonstrates a substantial positive influence on transaction intention (Kim et al. 2015; Kim and Ahn 2007).

\subsubsection{Retention and loyalty}

Customer retention can be achieved when one believes in the trustworthiness of an e-vendor and his/her ability in fulfilling promises, which in turn, increasing the possibility of repurchase intention (Hong and Cho 2011; Liu and Tang 2018). Customer loyalty in an online environment, also known as e-loyalty, refers to "an enduring psychological attachment by a customer to a particular online vendor or service provider" (Cyr et al. 2007, p. 44).

The direct and piercing impact of trust on retention (Qureshi et al. 2009) and e-loyalty (Carter et al. 2014) have been discussed in previous literature. For example, trust has been considered a factor engendering affective commitment, which helps develop an online customer's intention to revisit the website and purchase in the upcoming future (Liu and Tang 2018). As for trusting beliefs, when online consumers already establish trusting beliefs, they will hardly switch to other e-vendors because of the risk and uncertainty involved with finding a new online seller and difficulties associated with establishing a new trusting relationship (Carter et al. 2014). 


\subsubsection{Perception about seller}

To trust sellers, customers and buyers are expected to have an improved image of sellers, the appropriate technological conditions used for online transactions, and improved conditions of the services offered to. This feature comprises perceived usefulness of used technology, perceived enjoyment, perceived benefits, perceived value, price premium, and e-WOM intention about the seller. When buyers trust sellers as a result of an improved perception, they allow sellers to obtain premium prices and yield above-average profits (Klein and Leffler 1981; Shapiro 1983) to compensate seller transaction risks (Ba and Pavlou 2002).

\subsubsection{Satisfaction}

A desirable outcome of a trust-based relationship is satisfaction (Cannon 1999). When online customers trust a web vendor, they are likely to be satisfied with their transactions (Pavlou 2002). The relationship between trust and satisfaction has been investigated in many studies. For instance, Chang et al. (2016) investigated the effect of trust on satisfaction, indicating that customers' trust had significant and positive impacts on perceived satisfaction and transaction intention. Likewise, Pavlou (2002) stated that trust in the sellers' credibility positively influences buyers' satisfaction. Even recently, more studies have investigated a complicated relationship between trust, satisfaction, and transaction (Chang et al. 2016).

\subsubsection{Risk perception}

Finally, according to the literature, customers' and sellers' perceptions of the risks involved in an online transaction can be impacted by their trust in the other party. This relationship is different from research studies that considered risk perception an antecedent of trust (Gefen et al. 2003b). Perceived risk is defined as "the possibility of loss" and "an inherently subjective construct." However, the notion of risk is closely related to more general items and, consequently, emphasizes the possibility of economic loss (Dinev and Hart 2006). Electronic vendors try to reduce the risk perceptions of e-consumers through IT tools, e.g., third-party insurances (Gefen et al. 2008). In summary, trust can substantially help decrease negative risk perceptions toward an e-commerce context (Connolly and Bannister 2007; Guo et al. 2018; Shukla 2014; Heijden et al. 2001; Verhagen et al. 2006).

\section{Discussion}

This study presented a comprehensive and systematic review of antecedents and consequences of trust in online markets. Unlike the previous reviews, the present study considered both antecedents and consequences of trust from both customers' and sellers' points of view by providing a model using a synthesize of conceptually 
related theories in this area. Figure 4 illustrates a comprehensive model of trust based on my review of related studies in the literature.

Although the factors demonstrated in Fig. 4 have used with differing frequencies in the literature, their comprehensive and unified review can usefully provide a big picture of the research studies conducted earlier on this topic. This section will discuss these findings by listing potential implications for research and practice.

\subsection{Implications for research}

In answer to RQ3, we looked at the theoretical concepts and contextual dimensions in the literature beyond investigating the factors impacting on or being impacted by online trust. The present study can benefit future research in several different ways. First, reviewing the theories used in this area can help future studies identify their similarities and differences.

In addition, a synthesis of the theories used in the review can highlight the factors which have been less focused on. For example, the review of literatures indicates that little is known about interpreting trust by different parties. Therefore, in the current study, we suggest three future directions which can be conducted on online trust studies. First, future research can make perfect use of different models and theories, such as motivational model (Keller 1983) and accountability theory (Lerner and Tetlock 1999) to shed light on the less studied factors in online trust, like social presence, accountability, relevance, and confidence.

Furthermore, models and theories concerned with communication and media (Shannon and Weaver 1949; Toulmin 2003; Miller 1956) can be used to identify the way trust is understood and perceived in an online environment and the way it can be transferred to various situational contexts (Schultz 2006). Such theoretical perspectives can also be extended to explore the unobservable events that impact and

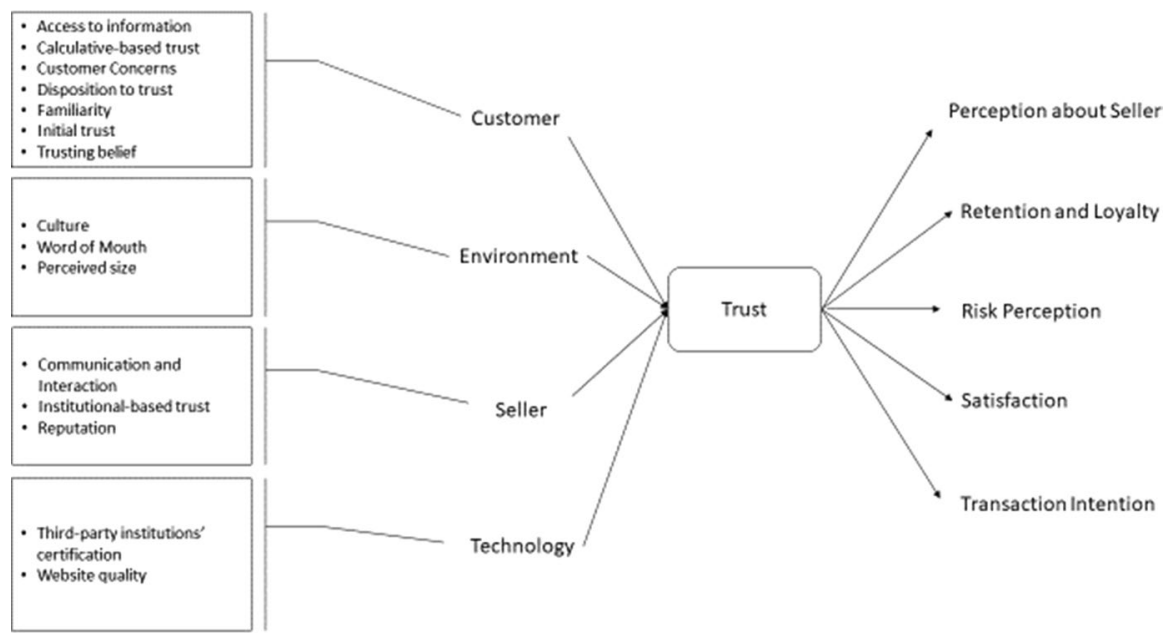

Fig. 4 A detailed model of antecedents and consequences of trust in e-commerce 
create trustworthiness in an online environment and give inter-subjective meaning to trust by different stakeholders in various contexts (Dobson et al. 2007; Phillips and Brown 1993). In terms of research approaches and perspectives, the literature, so far, seems to have ignored them. Future studies can benefit from available research design and methods (Hevner 2007; Gregor and Jones 2007) and extend the existing literature on prescriptive work to improving trust in e-commerce.

Moreover, as mentioned in the previous sections, most studies in the literature (almost 96\%) have focused on the mechanisms under which customers trust buyers, technology, and a community. Apart from customers, other stakeholders involved in an online transaction can receive considerable attention. In particular, sellers as trustees should be paid more attention in future research. Future studies should also go beyond available research on B2B e-commerce (Tsatsou et al. 2010; Pavlou 2002) and online auctions (Pavlou and Dimoka 2006) to focus on disruptive technologies that promote the position of customers in e-commerce (Hawlitschek et al. 2018). Such a trend brings new changes and possibilities to electronic markets in which customers are put a central position. Additionally, future research calls for more attention to new forms of transaction and technological advancements in payment such as blockchain and distributed ledger (Lacity 2018; Lindman et al. 2017) and how customers put trust in these technologies.

Surprisingly, the existing knowledge on trust in e-commerce in the literature seems to be very constrained in terms of demographic characteristics since most studies have mainly taken North American, European, and East Asian contexts into account. In the same way, there are rare studies addressing significant differences of trust in e-commerce platforms in developed and developing countries (Hajli 2019; Shareef et al. 2018). In terms of subjects' age, although a wide range of subjects differing in their age has been reported in studies in the literature (Hoffmann et al. 2014), many of which are usually targeted at subjects with young-age groups, like students. However, in the long term, this type of research will result in the exclusion of certain parts of society (Cushman et al. 2008). Therefore, future research on trust in e-commerce calls for the inclusion of a diversity of subjects, especially those who belong to the older generation of users.

\subsection{Implications for practice}

The present study is of high significance from different aspects. In effect, the classification proposed in this study is beneficial for practitioners, managers, and owners of e-commerce platforms and online businesses as they can be empowered to put those factors that influence customers' trust in e-commerce into practice to bring about improvements in their e-commerce platforms and online businesses. In particular, reliability, coherence, visual appearance, and website qualities that are likely to affect customers' trust in e-commerce could be enhanced. Likewise, to make buyers and customers trust more on e-commerce platforms, their owners can make use of a trusting third party or an intermediary. Also, practitioners need to consider 
online seals, encryption certificates, assurance, and guarantees in the process of trust.

Further, it will help practitioners to form new approaches to develop and refine the notion of trust in e-commerce flourishingly. Finally, as the current study suggested, e-commerce platform developers are required to be technologically accustomed to improving the conditions under which customers can trust their platforms.

\section{Conclusion}

Despite long-standing research conducted in the past two decades on trust in e-commerce environments, no comprehensive study has examined the research body of knowledge in this area, aimed to develop a comprehensive framework. Hence, this paper used a systematic literature review approach to investigate the factors that can impact trust in e-commerce platforms, as well as to find out its possible consequences. Based on my review of 129 papers in high-ranked IS journals and conferences, I identified various antecedents and consequences of trust.

Like any other review type of research, the study is not devoid of some limitations. For example, the study did not include those high-ranked journals and conferences that could not satisfy the designated metrics with respect to the topic of interest. Also, despite my attempts to form a comprehensive set of keywords, some of which may have been missed due to different terms that could be used in a specific interface. However, the study made an endeavour to be successful in developing a comprehensive framework in relation to trust among customers and sellers in e-commerce platforms using a synthesis of related theories in this area, which may be beneficial for future research and practice.

Acknowledgements I wish to express my sincere appreciation to Dr. Alireza Amrollahi, for his comments on the early version of this paper.

\section{References}

Agag GM, Khashan MA, Colmekcioglu N, Almamy A, Alharbi NS, Eid R et al (2020) Converting hotels website visitors into buyers How online hotel web assurance seals services decrease consumers ' concerns and increase online booking intentions. Inf Technol People 33(1):129-159

Ajzen I (1991) The theory of planned behavior. Organ Behav Hum Decis Process 50(2):179-211

Amrollahi A, Ghapanchi AH, Talaei-Khoei A (2013) A systematic literature review on strategic information systems planning: insights from the past decade. Pacif Asia J Assoc Inf Syst 5(2):39-66

Awad NF, Ragowsky A (2008) Establishing trust in electronic commerce through online word of mouth: an examination across genders. J Manag Inf Syst 24(4):101-121

Ba S, Pavlou PA (2002) Evidence of the effect of trust building technology in electronic markets: price premiums and buyer behavior. MIS Q 26:243-268

Barnes SJ (2020) Information management research and practice in the post-COVID-19 world. Int J Inf Manag 55:102175

Beldad A, De Jong M, Steehouder M (2010) How shall I trust the faceless and the intangible? A literature review on the antecedents of online trust. Comput Hum Behav 26(5):857-869

Bhattacherjee A (2002) Individual trust in online firms: Scale development and initial test. J Manag Inf Syst 19(1):211-241 
Bui SN, Kettinger WJ, Park I (2013) Personalization to new website users: the role of trust and culture. In: Proceedings of the nineteenth americas conference on information systems

Cannon JPA (1999) Buyer-seller relationships in business markets. J Mark Res 36(4):439-460

Carter M, Wright R, Thatcher JB, Klein R (2014) Understanding online customers' ties to merchants: the moderating influence of trust on the relationship between switching costs and e-loyalty. Eur J Inf Syst 23(2):185-204

Chang MK, Cheung W, Tang M (2013) Building trust online: Interactions among trust-building mechanisms. Inf Manag 50(7):439-445

Chang S-H, Chih W-H, Liou D-K, Yang Y-T (2016) The mediation of cognitive attitude for online shopping. Inf Technol People 29:618-646

Chiu CL, Chiu JL, Mansumitrchai S (2019) Stages in the development of consumers' online trust as mediating variable in online banking system: a proposed model. Int J Electr Finance 9(3):170-201

Chong B, Yang Z, Wong M (2003) Asymmetrical impact of trustworthiness attributes on trust, perceived value, and purchase intention: a conceptual framework for cross-cultural study on consumer perception of online auction. In Proceedings of the 5th international conference on Electronic commerce, pp 213-219

Clemons EK, Wilson J, Matt C, Hess T, Ren F, Jin F, Koh NS (2016) Global differences in online shopping behavior: Understanding factors leading to trust. J Manag Inf Syst 33(4):1117-1148

Coleman JS (1988) Social capital in the creation of human capital. Am J Sociol 94:S95-S120

Connolly R, Bannister F (2007) Consumer trust in Internet shopping in Ireland: towards the development of a more effective trust measurement instrument. J Inf Technol 22(2):102-118

Cushman M, McLean R, Zheng Y, Walsham G (2008) Inequality of what? Social exclusion in the e-society as capability deprivation. Inf Technol People

Cyr D, Hassanein K, Head M, Ivanov A (2007) The role of social presence in establishing loyalty in e-service environments. Interact Comput 19(1):43-56

Datta P, Chatterjee S (2008) The economics and psychology of consumer trust in intermediaries in electronic markets: the EM-trust framework. Eur J Inf Syst 17(1):12-28

Davis FD, Bagozzi RP, Warshaw PR (1989) User acceptance of computer technology: a comparison of two theoretical models. Manag Sci 35(8):982-1003

Dinev T, Hart P (2006) An extended privacy calculus model for e-commerce transactions. Inf Syst Res 17(1):61-80

Dobson P, Myles J, Jackson P (2007) Making the case for critical realism: examining the implementation of automated performance management systems. Inf Resour Manag J (IRMJ) 20(2):138-152

Ernst CG, Young (2000) Perceptions of trust. ECommerce Alerts Issued by Bennett Gold, Chartered Accountants

Fisher J, Shanks G, Lamp JW (2007) A ranking list for information systems journals. Aust J Inf Syst 14(2):5-15

Flavin C, Guinalu M, Gurrea R (2006) The role played by perceived usability, satisfaction and consumer trust on website loyalty. Inf Manag 43(1):1-14

Fung R, Lee M (1999) EC-trust (trust in electronic commerce): exploring the antecedent factors. AMCIS 1999:179

Gefen D, Benbasat I, Pavlou P (2008) A research agenda for trust in online environments. J Manag Inf Syst 24(4):275-286

Gefen D, Karahanna E, Straub DW (2003a) Trust and TAM in online shopping: an integrated model. MIS Q 27(1):51-90

Gefen D, Rao VS, Tractinsky N (2003b) The conceptualization of trust, risk and their relationship in electronic commerce: The need for clarifications. 192b

Giaglis GM, Klein S, O'Keefe RM (2002) The role of intermediaries in electronic marketplaces: developing a contingency model. Inf Syst J 12(3):231-246

Grabner-Kräuter S, Kaluscha EA (2003) Empirical research in online trust: a review and critical assessment. Int J Hum Comput Stud 58(6):783-812

Gregor S, Jones D (2007) The anatomy of a design theory. J Assoc Inf Syst 8(5):312-335

Guo Y, Bao Y, Stuart BJ, Le-Nguyen K (2018) To sell or not to sell: exploring sellers' trust and risk of chargeback fraud in cross-border electronic commerce. Inf Syst J 28(2):359-383

Hajli N (2019) The impact of positive valence and negative valence on social commerce purchase intention. Inf Technol People

Hawlitschek F, Notheisen B, Teubner T (2018) The limits of trust-free systems: A literature review on blockchain technology and trust in the sharing economy. Electron Commer Res Appl 29:50-63 
Heijden HVD, Verhagen T, Creemers M (2001) Predicting online purchase behavior: replications and tests of competing models. In: Proceedings of the 34th Annual Hawaii international conference on system sciences

Hennig-Thurau T, Gwinner KP, Walsh G, Gremler DD (2004) Electronic word-of-mouth via consumeropinion platforms: what motivates consumers to articulate themselves on the Internet? $\mathrm{J}$ Interact Mark 18(1):38-52

Hevner AR (2007) A three cycle view of design science research. Scand J Inf Syst 19(2):4

Hoffmann CP, Lutz C, Meckel M (2014) Digital natives or digital immigrants? The impact of user characteristics on online trust. J Manag Inf Syst 31(3):138-171

Hofstede G, Hofstede GJ, Minkov M (2010) Cultures and organizations: software of the mind. Revised and expanded, 3rd edn. McGraw-Hill, New York

Hong IB, Cho H (2011) The impact of consumer trust on attitudinal loyalty and purchase intentions in B2C e-marketplaces: intermediary trust vs seller trust. Int J Inf Manag 31(5):469-479

Huang L-T, Farn C-K, Yin K-L (2005) On initial trust-building for e-commerce: revisiting from the perspective of signal theory and trust transference. In: ECIS 2005 Proceedings, p 94

Huang S-Y, Li C-R, Lin C-J (2007) A literature review of online trust in business to consumer e-commerce transactions 2001-2006. Inf Syst 8(2):63-69

Hwang Y (2005) An empirical study of online trust and consumer behavior: cultural orientation, social norms, and personal innovativeness in information technology. In: ICIS 2005 Proceedings, p 69

Jarvenpaa SL, Tractinsky N, Vitale M (2000) Consumer trust in an Internet store. Inf Technol Manag 1(1-2):45-71

Jones K, Leonard LN (2008) Trust in consumer-to-consumer electronic commerce. Inf Manag 45(2):88-95

Keller JM (1983) Motivational design of instruction. Instruct Des Theor Models Overv Their Curr Status 1(1983):383-434

Kim DJ (2008) Self-perception-based versus transference-based trust determinants in computer-mediated transactions: a cross-cultural comparison study. J Manag Inf Syst 24(4):13-45

Kim M-S, Ahn JH (2007) Management of trust in the e-marketplace: the role of the buyer's experience in building trust. J Inf Technol 22(2):119-132

Kim D, Benbasat I (2006) The effects of trust-assuring arguments on consumer trust in Internet stores: application of Toulmin's model of argumentation. Inf Syst Res 17(3):286-300

Kim S, Park H (2013) Effects of various characteristics of social commerce (s-commerce) on consumers' trust and trust performance. Int J Inf Manage 33(2):318-332

Kim Y, Peterson RA (2017) A meta-analysis of online trust relationships in e-commerce. J Interact Mark 38:44-54

Kim DJ, Ferrin DL, Rao HR (2009) Trust and satisfaction, two stepping stones for successful e-commerce relationships: a longitudinal exploration. Inf Syst Res 20(2):237-257

Kim DJ, Sugumaran V, Rao HR (2015) Web assurance seal services, trust and consumers ' concerns: an investigation of e-commerce transaction intentions across two nations. Eur J Inf Syst 1-22

Kit M, Cheung W, Tang M (2013) Building trust online: interactions among trust building mechanisms. Inf Manag 50:439-445

Kitchenham B (2004) Procedures for performing systematic reviews. Keele UK, Keele Univ 33(2004):1-26

Klein B, Leffler KB (1981) The role of market forces in assuring contractual performance. J Polit Econ 89(4):615-641

Lacity MC (2018) Addressing key challenges to making enterprise blockchain applications a reality. MIS Q Exec 17(3):201-222

Lerner JS, Tetlock PE (1999) Accounting for the effects of accountability. Psychol Bull 125(2):255

Li X, Hess TJ, Valacich JS (2008) Why do we trust new technology? A study of initial trust formation with organizational information systems. J Strateg Inf Syst 17(1):39-71

Li X, Rong G, Thatcher JB (2009) Do we trust the technology? People? or both? Ruminations on technology trust. In: AMCIS 2009 proceedings, p 459

Li H, Aham-Anyanwu N, Tevrizci C, Luo X (2015) The interplay between value and service quality experience: e-loyalty development process through the eTailQ scale and value perception. Electron Commer Res 15(4):585-615

Lim KH, Sia C, Lee MKO, Benbasat I (2006) Do I trust you online, and if so, will I buy? An empirical study of two trust-building strategies. J Manag Inf Syst 23(2):233-266 
Lindman J, Tuunainen VK, Rossi M (2017) Opportunities and risks of blockchain technologies-a research agenda. In: Proceedings of the 50th Hawaii international conference on system sciences

Liu Y, Tang X (2018) The effects of online trust-building mechanisms on trust and repurchase intentions: an empirical study on eBay. Inf Technol People 31:666-687

Luhmann N (2018) Trust and power. Wiley, New York

Mayer RC, Davis JH, Schoorman FD (1995) An integrative model of organizational trust. Acad Manag Rev 20(3):709-734

Mazzella F, Sundararajan A, d'Espous VB, Möhlmann M (2016) How digital trust powers the sharing economy. IESE Bus Rev 26(5):24-31

McKnight DH (2005) Trust in information technology. Blackwell Encycl Manag 7:329-331

McKnight DH, Chervany NL (2001) What trust means in e-commerce customer relationships: an interdisciplinary conceptual typology. Int J Electron Commer 6(2):35-59

McKnight DH, Choudhury V, Kacmar C (2002) Developing and validating trust measures for e-commerce: an integrative typology. Inf Syst Res 13(3):334-359

Miller GA (1956) The magical number seven, plus or minus two: some limits on our capacity for processing information. Psychol Rev 63(2):81

Papadopouou P, Kanellis P, Martakos D (2001) Investigating trust in e-commerce: a literature review and a model for its formation in customer relationships. In: AMCIS 2001 proceedings, p 155

Pavlou PA (2002) Institution-based trust in interorganizational exchange relationships: the role of online B2B marketplaces on trust formation. J Strateg Inf Syst 11(3-4):215-243

Pavlou PA, Dimoka A (2006) The nature and role of feedback text comments in online marketplaces: implications for trust building, price premiums, and seller differentiation. Inf Syst Res 17(4):392-414

Pavlou PA, Fygenson M (2006) Understanding and predicting electronic commerce adoption: an extension of the theory of planned behavior. MIS Q 30:115-143

Pavlou PA, Gefen D (2004) Building effective online marketplaces with institution-based trust. Inf Syst Res 15(1):37-59

Pennington R, Wilcox HD, Grover V (2003) The role of system trust in business-to-consumer transactions. J Manag Inf Syst 20(3):197-226

Phillips N, Brown JL (1993) Analyzing communication in and around organizations: a critical hermeneutic approach. Acad Manag J 36(6):1547-1576

Qureshi I, Fang Y, Ramsey E, McCole P, Ibbotson P, Compeau D (2009) Understanding online customer repurchasing intention and the mediating role of trust-an empirical investigation in two developed countries. Eur J Inf Syst 18(3):205-222

Resnick P, Zeckhauser R (2002) Trust among strangers in internet transactions: empirical analysis of ebay's reputation system. Econ Internet E-Commerce 11(2):23-25

Schryen G, Wagner G, Benlian A, Paré G (2020) A knowledge development perspective on literature reviews: validation of a new typology in the IS field. In: Communications of the AIS, p 46

Schultz CD (2006) A trust framework model for situational contexts. In: Proceedings of the 2006 international conference on privacy, security and trust: bridge the gap between PST technologies and business services, pp 1-7

Shankar V, Urban GL, Sultan F (2002) Online trust : a stakeholder perspective, concepts, implications, and future directions. J Strat Inf Syst 11:325-344

Shannon CE, Weaver W (1949) The mathematical theory of com-munication. University of Illinois Press, Urbana, p 96

Shapiro C (1983) Premiums for high quality products as returns to reputations. Q J Econ 98(4):659-679

Shareef MA, Dwivedi YK, Kumar V, Davies G, Rana N, Baabdullah A (2018) Purchase intention in an electronic commerce environment. Inf Technol People

Shiau WL, Chau PYK (2015) Does altruism matter on online group buying? Perspectives from egotistic and altruistic motivation. Inf Technol People 28(3):677-698

Shukla P (2014) The impact of organizational efforts on consumer concerns in an online context. Inf Manag 51(1):113-119

Sia C, Lim KH, Lee MKO, Benbasat I (2009) Web strategies to promote internet shopping: is culturalcustomization needed? MIS Q 33(2009):491-512

Spence AM (1974) Market signaling: informational transfer in hiring and related screening processes. Harvard University Press, Cambridge, p 143

Sun H (2010) Sellers' trust and continued use of online marketplaces. J Assoc Inf Syst 11(4):2 
Sun H, Zhang P (2008) Online sellers trust and use of online auction marketplaces. In: PACIS 2008 proceedings, $\mathrm{p} 78$

Tallon PP, Queiroz M, Coltman T, Sharma R (2019) Information technology and the search for organizational agility: a systematic review with future research possibilities. J Strat Inf Syst 28(2):218-237

Tomlinson EC, Schnackenberg AK, Dawley D, Ash SR (2020) Revisiting the trustworthiness-trust relationship: exploring the differential predictors of cognition-and affect-based trust. J Organ Behav 41(6):535-550

Toulmin SE (2003) The uses of argument. Cambridge University Press, Cambridge

Tsatsou P, Elaluf-Calderwood S, Liebenau J (2010) Towards a taxonomy for regulatory issues in a digital business ecosystem in the EU. J Inf Technol 25(3):288-307

Venkatesh V, Davis FD (2000) A theoretical extension of the technology acceptance model: four longitudinal field studies. Manag Sci 46(2):186-204

Verdon J (2021) Global E-Commerce Sales To Hit \$4.2 Trillion As Online Surge Continues, Adobe Reports. Forbes. https://www.forbes.com/sites/joanverdon/2021/04/27/global-ecommerce-sales-tohit-42-trillion-as-online-surge-continues-adobe-reports/?sh=77033a450fd4

Verhagen T, Meents S, Tan YH (2006) Perceived risk and trust associated with purchasing at electronic marketplaces. Eur J Inf Syst 15(6):542-555

Wang W, Benbasat I (2008) Attributions of trust in decision support technologies: a study of recommendation agents for e-commerce. J Manag Inf Syst 24(4):249-273

Woisetschläger DM, Lentz P, Evanschitzky H (2011) How habits, social ties, and economic switching barriers affect customer loyalty in contractual service settings. J Bus Res 64(8):800-808

Publisher's Note Springer Nature remains neutral with regard to jurisdictional claims in published maps and institutional affiliations. 